\title{
COHORT PROFILE: The Complications of Long-Term Antiretroviral Therapy study in Uganda (CoLTART), a prospective clinical cohort
}

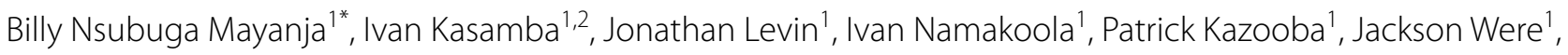
Pontiano Kaleebu ${ }^{1,3}$, Paula Munderi ${ }^{1}$ and on behalf of the CoLTART study team

\begin{abstract}
Background: Antiretroviral therapy (ART) improves the survival and quality of life of HIV-positive individuals, but the effects of long-term ART use do eventually manifest. The Complications of Long-Term Antiretroviral Therapy cohort study in Uganda (CoLTART) was established to investigate the metabolic and renal complications of long-term ART use among Ugandan adults. We describe the CoLTART study set-up, aims, objectives, study methods, and also report some preliminary cross-sectional study enrolment metabolic and renal complications data analysis results.

Methods: HIV-positive ART naïve and experienced adults (18 years and above) in Uganda were enrolled. Data on demographic, dietary, medical, social economic and behaviour was obtained; and biophysical measurements and a clinical examination were undertaken. We measured: fasting glucose and lipid profiles, renal and liver function tests, full blood counts, immunology, virology and HIV drug resistance testing. Plasma samples were stored for future studies.

Results: Between July 2013 and October 2014, we enrolled 1095 individuals, of whom 964 (88.0\%) were ART experienced (6 months or more), with a median of 9.4 years (IQR 7.0-9.9) on ART. Overall, 968 (88.4\%) were aged 35 years and above, 711 (64.9\%) were females, 608 (59.6\%) were or had ever been on a Tenofovir ART regimen and 236 (23.1\%) on a Protease Inhibitor (PI) regimen. There were no differences in renal dysfunction between patients on Tenofovir and Non-Tenofovir containing ART regimens. Patients on PI regimens had higher total cholesterol, lower high density lipoprotein, higher low density lipoprotein, higher triglycerides, and a high atherogenic index for plasma than the non-PI regimen, $p=0.001$ or $<0.001$. Patients on Non-PI regimens had higher mean diastolic hypertension than patients on Pl regimens, $\mathrm{p}<0.001$.

Conclusions: Our finding of no differences in renal dysfunction between patients on Tenofovir and those on NonTenofovir containing ART regimens means that Tenofovir based first line ART can safely be initiated even in settings without routine renal function monitoring. However, integration of cardiovascular risk assessment, preventive and curative measures against cardiovascular disease are required. The CoLTART cohort is a good platform to investigate the complications of long-term ART use in Uganda.
\end{abstract}

Keywords: Cohort profile, Antiretroviral therapy, Metabolic abnormalities, Renal complications, HIV, Uganda

*Correspondence: billy.mayanja@mrcuganda.org;

billymayanja@yahoo.com

${ }^{1}$ MRC/UVRI Uganda Research Unit on AIDS, P.O. Box 49, Entebbe, Uganda

Full list of author information is available at the end of the article 


\section{Background}

Since the Universal roll-out of antiretroviral therapy (ART) in 2004, access to and availability of ART has improved. By June 2016, globally 18.2 million HIV-positive people were receiving ART, up from 15.8 million in June 2015 and 7.5 million in 2010 [1]. In Uganda, 750,896 (50\%) HIV-positive people were receiving ART by December 2014 [2]. Although in industrialised countries ART has been used for over 20 years, in sub-Sahara, ART availability in public health facilities only began around 2004. In Uganda, reports suggest that the prevalence of non-infectious diseases like diabetes mellitus, and cardiovascular morbidity and mortality are increasing [3, 4].

Long-term ART use is associated with metabolic, cardiovascular, hepatic, renal, bone, bone marrow and other complications or toxicities [5-9]. These complications of ART are variably associated with all major classes of ARVs. The three most common metabolic abnormalities that are related to ART are dyslipidaemia, lipodystrophy and dysregulation of glucose metabolism [5-9]. Renal impairment among HIV-positive individuals may be due to HIV associated nephropathy, co-infections and comorbidities, or renal toxicity from ART and concurrent medications $[10,11]$. Due to its cost, in resource limited settings Tenofovir had been reserved for use with Protease inhibitors in second line ART regimens. The WHO recommendation to use Tenofovir in first line ART regimens has been widely adopted by ART programmes in Africa including Uganda, Kenya and Tanzania [12-15]. However, Tenofovir is often associated with renal toxicity, manifesting as a decline in estimated glomerular filtration rate (eGFR), proximal renal tubular dysfunction and acute renal failure especially among patients with risk factors for kidney disease [16-23]. It has been suggested, that patients of African origin are at higher risk for HIV associated kidney disease [24], a suggestion that remains to be clarified by studies conducted in Africa. Therefore, for long-term HIV care in Africa, health workers need research-based evidence on renal function beyond 5 years of Tenofovir containing ART, and how these patients should be monitored.

In sub-Saharan Africa, there is scarce literature on the long-term impact of ARVs toxicities among African populations. Current ART guidelines in sub-Saharan Africa are therefore based on evidence from industrialised country settings. However, there are differences between industrialised countries and sub-Saharan Africa in terms of patient profiles, background risk factors for co-infections, co-morbidities, ART regimen choices and drug toxicities. In 2013, the Complications of Long-Term Antiretroviral Therapy (CoLTART) cohort was therefore established by the MRC/UVRI Uganda Research Unit on AIDS (MRC/UVRI Uganda Unit) as a platform for studying the complications of long-term ART among Ugandan HIV-positive adults. The study aimed at examining the metabolic and renal complications of longterm ART use among Ugandan HIV-positive adults aged 18 years and above. In this paper, we describe the CoLTART study set-up, aims, objectives, study methods, and also report some preliminary cross-sectional study enrolment renal and metabolic complications data analysis results.

\section{Methods}

\section{The CoLTART study design and settings}

The CoLTART study was a prospective clinical cohort conducted at two study clinics; (a) the former Development of Antiretroviral therapy in Africa (DART) Trial study clinic in Entebbe [25], and (b) the former Rural Clinical Cohort (RCC) study clinic in Kyamulibwa, approximately 120 kilometres from Entebbe [26]. The MRC/UVRI Uganda Unit's Head offices and central Clinical Diagnostic Laboratory Services (CDLS) are located in Entebbe.

\section{CoLTART study aims and objectives}

The CoLTART study aims were to study the metabolic and renal complications of long-term ART, and the long-term treatment outcomes of a triple nucleoside first ART regimen. The primary objectives were to compare the: (a) mean values for cardio-metabolic markers among patients on a Protease Inhibitor (PI)-containing ART regimen and those on a non PI-containing regimen. (b) Mean values of proximal renal tubular function and eGFR among patients on a Tenofovir (TDF) containing regimen and those on a non-TDF containing regimen.

\section{CoLTART study participants}

Between July 2013 and October 2014, CoLTART study participants (Fig. 1) who were HIV-positive adults (aged 18 and above) on ART were recruited from; (a) the former DART Trial Cohort, which was a randomised clinical trial of monitoring strategy for the management of ART in adults with HIV infection in Africa established in 2003 [25]. (b) The former RCC which was an open clinical cohort established in 1990 to study the natural history of HIV infection [26] and later the impact of ART after its introduction in 2004 [27-30]. ART naïve HIVpositive study participants, but who were eligible to initiate ART were enrolled from: (a) the RCC, (b) the General Population Cohort that was established in 1989 in rural southwest Uganda to examine the dynamics of the HIV epidemic [31] and (c) the Entebbe Pre-ART cohort that was established in 1995 as a double blind, randomised and placebo controlled trial of a 23-valent pneumococcal polysaccharide vaccine in HIV-positive adult Ugandans 


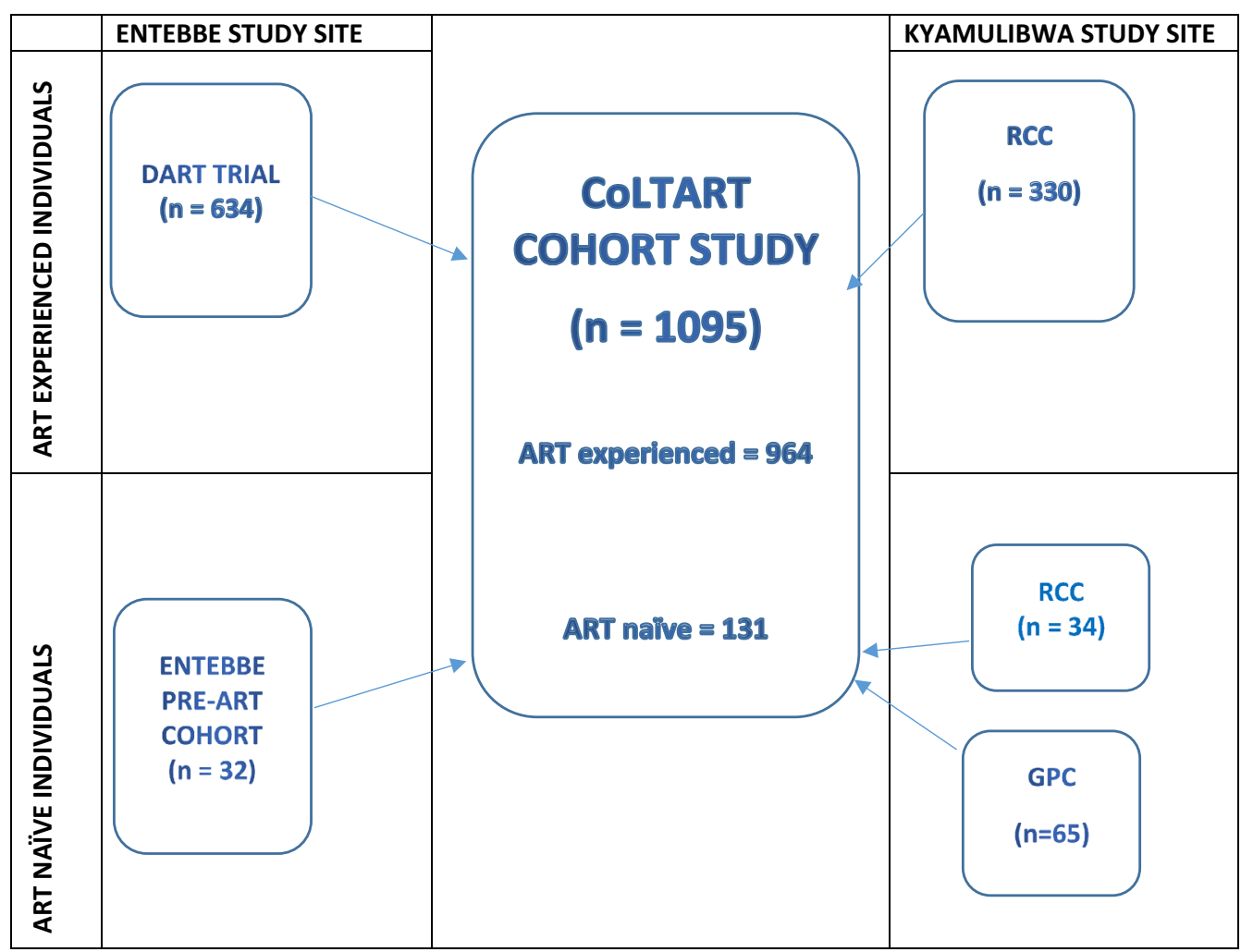

Fig. 1 Sources of enrolled CoLTART cohort study participants

[32]. ART was provided according to existing National ART guidelines [13, 33]. The study included HIV-positive adults (aged 18 years and above), who were on ART or eligible to initiate ART, not participating in another study, who were willing to undergo regular clinical, biophysical and laboratory evaluation and to complete a study questionnaire. Individuals who were too sick to undergo study procedures, unable or unwilling to give informed consent were excluded from the study.

\section{Participants' enrolment and follow-up}

Consenting eligible individuals were enrolled, and requested to fast from midnight of the day prior enrolment, and they received a drink and snack after the blood draw and biophysical measurements. We measured the body weight using the Seca digital measuring scale, height using a portable Seca 213 Leicester stadiometer and body circumferences using a non-stretchable Seca 201 Ergonomic Circumference Measuring tape (Table 1). Details of the methods for taking biophysical measurements and calibrating the equipment used have been described elsewhere [34]. Blood pressure and pulse rate were measured using the Omron M6 comfort automatic blood pressure monitor. At enrolment and six monthly follow-up visits, a modified WHO STEPS cardiovascular risk data surveillance questionnaire was administered to collect the relevant data [35]. Every three months, participants renewed their prescriptions for ART and/or cotrimoxazole or Dapsone prophylaxis and adherence data was collected using self-report and pill count. Every 6 months (Table 1), participants attended for scheduled follow-up visits, and they fasted as done at enrolment, and the data collected were recorded on a follow-up questionnaire and clinical examination form. At these 6 monthly visits, participants also renewed their medicines prescriptions and adherence data was collected. Participants who fell sick in between the scheduled visits attended the study clinics to receive medical care.

\section{Laboratory procedures Specimen collection and storage}

At enrolment and follow-up visits, about $10-15 \mathrm{ml}$ of venous blood were collected in three tubes as follows: (a) $4 \mathrm{ml}$ of whole blood in an EDTA tube for haematology, immunology and viral loads measurements. (b) $5 \mathrm{ml}$ plain serum tube blood to measure fasting serum lipids; renal and liver function tests. (c) $4 \mathrm{ml}$ Sodium fluoride tube blood to measure fasting blood glucose. At enrolment only, serum for hepatitis B serology and two aliquots of plasma were stored at $-80^{\circ} \mathrm{C}$ for future testing. 
Table 1 Measurements and data collected in the CoLTART cohort

\begin{tabular}{|c|c|}
\hline Phase & Data collected at enrolment \\
\hline $\begin{array}{l}\text { Baseline } \\
\text { July } 2013\end{array}$ & $\begin{array}{l}\text { Demographic data and self-reported social economic status } \\
\text { Medical, dietary and socio-economic and behavioural risk factors } \\
\text { Biophysical measurements: weight, height, blood pressure, pulse rate; waist, hip and mid-upper arm circumferences } \\
\text { Clinical examination } \\
\text { Antiretroviral therapy and cotrimoxazole/dapsone adherence } \\
\text { Laboratory measurements data } \\
\text { Biochemistry } \\
\text { (i) Fasting blood lipid profiles: total cholesterol, triglycerides, low density lipoproteins, high density lipoproteins } \\
\text { (ii) Fasting blood glucose } \\
\text { (iii) Renal function tests: urine strip testing, phosphates and creatinine } \\
\text { Serum phosphates, creatinine and urea } \\
\text { (vi) Liver function tests: alanine transaminase, aspartate transaminase, alkaline phosphatase and bilirubin } \\
\text { Haematology and immunology } \\
\text { (i) Full blood counts } \\
\text { (ii) CD3, CD4 and CD8 cell counts } \\
\text { Virology } \\
\text { (i) HIV viral loads } \\
\text { (ii) HIV drug resistance testing —-when indicated } \\
\text { Serology (for future testing) } \\
\text { Serum for Hepatitis B virus serology and plasma aliquots stored at - } 80^{\circ} \mathrm{C}\end{array}$ \\
\hline $\begin{array}{l}6 \text { monthly } \\
\text { Follow-up } \\
\text { January } 2014\end{array}$ & $\begin{array}{l}\text { Data collected at follow up } \\
\text { Biophysical measurements } \\
\text { Medical, dietary and socio-economic and behavioural risk factors } \\
\text { Clinical examination } \\
\text { Antiretroviral therapy and cotrimoxazole/dapsone adherence } \\
\text { Laboratory measurements } \\
\text { Fasting blood glucose and lipid profiles } \\
\text { Renal and liver function tests } \\
\text { Full blood counts and immunology-CD3, CD4 and CD8 } \\
\text { HIV viral loads } \\
\text { HIV drug resistance testing-when indicated } \\
\text { Whole blood for genomics studies stored at }-80^{\circ} \mathrm{C} \text { (once) }\end{array}$ \\
\hline
\end{tabular}

Blood tubes were labelled with a unique individual study and laboratory number and transferred under appropriate conditions to the CDLS laboratory for analysis. At one follow-up visit, a $4 \mathrm{ml}$ of whole blood sample in an EDTA tube was stored at $-80^{\circ} \mathrm{C}$ for future genomics testing. Participants with viral loads of 1000 copies/ $\mathrm{ml}$ or higher had antiretroviral drug resistance testing done. Participants (excluding women in their menses) provided a fresh midstream urine specimen in a plain sterile container, that was later portioned in two plastic centrifuge tubes (one plain for urine creatinine and the other acidified for urine phosphates measurements), and a dipstick strip test was done on the urine remaining in the container.

\section{Laboratory testing}

All samples were analysed in the MRC/UVRI Uganda Unit's CDLS laboratories. The Clinical chemistry analyser, COBAS Integra 400 plus (Roche Diagnostics) was used to measure fasting serum lipids and blood glucose, and renal and liver function test parameters. Full blood counts were measured using the Coulter AcT5 Diff CP Analyser (Beckman Coulter, USA). CD4 cell counts were measured using either the FACSCount or FACSCalibur machine (Becton-Dickinson, USA). Plasma HIV-1 RNA was quantified using the COBAS Ampliprep/Taqman V2.0 HIV-1 viral load assay (Roche Molecular Diagnostics [RMD], NJ, USA) with a lower detection limit of 20 copies/ml. For urine strip testing, we used the Siemens Multistix 10SG and read with Clinitek Status Analyzer (Siemens Healthcare Diagnostics). For ARV drug resistance, PCR and sequencing reactions were conducted and the sequences submitted to the Stanford University HIV Drug Resistance database. The surveillance drug resistance mutations were identified using the 2009 WHO list for surveillance of transmitted drug resistances [36], using the Stanford calibrated population resistance analysis tool version 5.0 beta [37]. Sequences with genetic mixtures of wild-type and mutant sequences at amino acid sites that code for SDRMs were considered to be drug-resistant.

\section{Laboratory data quality assurance}

Standard operating procedures and internal quality measurements ensured internal quality control. The United Kingdom National External Quality Assurance Service, College of American Pathologists and the Royal College of Pathologists of Australasia were used for 
External quality Assurance for both haematological and biochemistry assays. Virology Quality Assurance Scheme (Rush University, Chicago, IL) was used for External Quality Assurance for virological assays.

\section{Data management and statistical methods}

Data was collected on the case report forms which together with the Laboratory result forms were sorted, batched and submitted to the Statistics section for data entry. Data was managed in accordance with the ICHGCP data management principles using a single Ms. Access study database using common identifiers to incorporate relevant retrospective data from the DART Trial Cohort and RCC databases. All the data was backed up on a central Unit server with a password restricted access. Enrolment statistical analyses were done in STATA 13 (Stata Corporation, College Station, USA). Participants' socio-demographic and economic characteristics, lifestyle and anthropometric as well as clinical, history of diseases and ART exposure were examined across study sites and by sex. Renal function outcomes were determined using measured renal function tests, and calculated Fractional Tubular reabsorption of phosphates and estimated glomerular filtration rate (eGFR). Different formulae were used to calculate eGFR; (a) the Cockcroft-Gault formulae with and without body surface area adjustment, (b) the Modified Diet in Renal Disease formulae with race adjustment and (c) the Chronic Kidney Disease Epidemiology.

Abnormal renal function outcomes were defined as: serum urea of more than $11.9 \mathrm{mmol} / \mathrm{l}$, serum creatinine of more than $109 \mu \mathrm{mol} / \mathrm{l}$, Fractional Tubular phosphates reabsorption of less than $82 \%$ and eGFR less than $60 \mathrm{ml} /$ $\min / 1.73 \mathrm{~m}^{2}$, Diabetis mellitus as a measured fasting blood glucose more than or equal to $6.4 \mathrm{mmol} / \mathrm{l}$ or history of and or being on medications for diabetis mellitus. Hypertension was a measured systolic blood pressure (SBP) of more than or equal to $140 \mathrm{mmHg}$ or diastolic blood pressure (DBP) more than or equal to $90 \mathrm{mmHg}$ or any history of and or being on medications for hypertension. The renal function outcomes were compared across the Tenofovir exposure groups: (i) non-Tenofovir containing ART regimen (Non-TDF), (ii) Tenofovir containing ART regimen (TDF-ART) and (iii) previously on Tenofovir containing ART regimen but stopped (TDFstopped). Mean values of renal function outcomes were compared by Tenofovir exposure using general linear models. General linear regression models adjusted for several factors were used to compare mean values of renal function outcomes across groups of Tenofovir exposure categories. The mean values of SBP, DBP, total serum cholesterol, high density lipoprotein, low density lipoprotein, triglyceride, atherogenic index of plasma and fasting blood glucose and Framingham risk score were compared between PI-based and non-PI based ART regimens using general linear regression models, adjusted for duration on ART and other factors.

\section{Results}

Between July 2013 and October 2014, we assessed 1108 HIV-positive individuals for study eligibility, of whom 1095 (98.8\%) were enrolled into the study. At the Entebbe site, 673 individuals were assessed for study eligibility and $666(99.0 \%)$ were enrolled and 7 (1.0\%) were not enrolled because; $3(0.4 \%)$ were participating in another study, $3(0.4 \%)$ did not return for enrolment while 1 (0.1\%) died before enrolment. At the Kyamulibwa site, 436 individuals were assessed for study eligibility and 429 (98.4\%) were enrolled, 7 (1.6\%) were not enrolled because $3(0.7 \%)$ requested for transfer to other ART care centres, $1(0.2 \%)$ had mental illness, $1(0.2 \%)$ declined consent for participation, $1(0.2 \%)$ defaulted and $1(0.2 \%)$ died before enrolment. Of the 1095 individuals enrolled, 964 (88.0\%) were ART experienced (6 months or more) with a median of 9.4 years (IQR 7.0-9.9) on ART. Overall, 968 (88.4\%) were aged 35 years and above, 711 (64.9\%) were females, 608 (59.6\%) were or had ever been on a Tenofovir containing ART regimen and 236 (23.1\%) on a Protease Inhibitor containing ART regimen. Participants at the urban (Entebbe) site were older, mean age (SD); 46.1 (8.1) vs 42.7 (10.6) years and had a higher education level; $54.3 \%$ vs $15.4 \%$ had attained secondary level education and above. Whereas most of rural participant were peasants (69.5\%), those from the urban site were mainly in gainful employment or self-employed-80.3\% (Table 2).

Among our study population, the overall prevalence of hypertension was $14.5 \%$, Diabetes mellitus-2.1\% and renal disease- $-0.6 \%$. Participants from the urban site had been on ART for a longer duration, with $90.7 \%$ on ART for 9 years and over compared to $11.7 \%$ at the rural site. Overall, 236 (23.1\%) of our participants were on a PI containing ART regimen with a higher proportion of patients being at the urban Entebbe site; 32.4\% compared to $7.6 \%$ among those at the rural Kyamulibwa site and 608 (59.6\%) were or had ever been on a Tenofovir containing ART regimen; $78.3 \%$ of those at the urban site and $28.3 \%$ at the rural site (Table 3 ). We found that among individuals on long-term ART; (a) there were no differences in renal dysfunction (glomerular function and renal tubular function) between patients on Tenofovir containing and Non-Tenofovir containing ART regimens (Table 4). (b) Patients on PI containing ART regimens had higher total cholesterol, lower high density lipoprotein, higher low density lipoprotein, higher triglycerides, and a high atherogenic index for plasma than patients on non-PI containing ART regimen, $\mathrm{p}=0.001$ or $<0.001$. (c) 
Table 2 Characteristics of participants at enrolment into the CoLTART study by sex and study site

\begin{tabular}{|c|c|c|c|c|c|c|c|}
\hline \multirow[t]{3}{*}{ Characteristic } & \multirow{3}{*}{$\begin{array}{l}\text { All combined } \\
\text { n (\%) }\end{array}$} & \multicolumn{3}{|c|}{ Entebbe site } & \multicolumn{3}{|c|}{ Kyamulibwa site } \\
\hline & & \multirow[t]{2}{*}{ All, n (\%) } & \multicolumn{2}{|l|}{ Sex } & \multirow[t]{2}{*}{ All, n (\%) } & \multicolumn{2}{|l|}{ Sex } \\
\hline & & & Females, n (\%) & Males, n (\%) & & Females, n (\%) & Males, n (\%) \\
\hline All by site & 1095 & 666 & $459(68.9)$ & $207(31.1)$ & 429 & $252(58.7)$ & $177(41.3)$ \\
\hline \multicolumn{8}{|l|}{ Age, years } \\
\hline $18-34$ & $127(11.6)$ & $34(5.1)$ & $29(6.3)$ & $5(2.4)$ & $93(21.8)$ & $65(26.0)$ & $28(15.8)$ \\
\hline $35-49$ & $649(59.3)$ & $426(64.0)$ & $295(64.3)$ & $131(63.3)$ & $222(52.0)$ & $126(50.4)$ & $96(54.2)$ \\
\hline $50+$ & $319(29.1)$ & $206(30.9)$ & $135(29.4)$ & $71(34.3)$ & $112(26.2)$ & $59(23.6)$ & $53(30.0)$ \\
\hline Mean age, years (SD) & $44.8(9.3)$ & $46.1(8.1)$ & $45.5(8.1)$ & $47.3(7.9)$ & $42.7(10.6)$ & $41.6(10.4)$ & $44.3(10.8)$ \\
\hline \multicolumn{8}{|l|}{ Marital status } \\
\hline Never married & $87(8.0)$ & $28(4.2)$ & $24(5.2)$ & $4(1.9)$ & $59(13.8)$ & $40(15.9)$ & 19 (10.7) \\
\hline Married/cohabiting & $469(42.8)$ & $263(39.5)$ & $105(22.9)$ & $158(76.3)$ & $206(48.0)$ & $93(36.9)$ & $113(63.8)$ \\
\hline Separated/divorced & $265(24.2)$ & $150(22.5)$ & $126(27.5)$ & $24(11.6)$ & $115(26.8)$ & $78(31.0)$ & $37(20.9)$ \\
\hline Widowed & $274(25.0)$ & $225(33.8)$ & $204(44.4)$ & $21(10.1)$ & $49(11.4)$ & $41(16.2)$ & $8(4.5)$ \\
\hline \multicolumn{8}{|l|}{ Education level } \\
\hline Incomplete primary & $498(45.5)$ & $185(27.8)$ & $133(29.0)$ & $52(25.1)$ & $313(73.0)$ & $181(71.8)$ & $132(74.6)$ \\
\hline Complete primary & $169(15.4)$ & $119(17.9)$ & $85(18.5)$ & $34(16.4)$ & $50(11.6)$ & $27(10.7)$ & $23(13.0)$ \\
\hline Secondary+ & $428(39.1)$ & $362(54.3)$ & $241(52.5)$ & $121(58.5)$ & $66(15.4)$ & $44(17.5)$ & $22(12.4)$ \\
\hline \multicolumn{8}{|l|}{ Employment $^{a}$} \\
\hline Peasant/farmer & $362(33.1)$ & $64(9.6)$ & $45(9.8)$ & $19(9.2)$ & $298(69.5)$ & $179(71.0)$ & $119(67.2)$ \\
\hline Gainful employment & $221(20.2)$ & $174(26.2)$ & $113(24.7)$ & $61(29.5)$ & $47(11.0)$ & $26(10.3)$ & $21(11.9)$ \\
\hline Self-employed/business & $427(39.0)$ & $360(54.1)$ & $242(52.8)$ & $118(57.0)$ & $67(15.6)$ & $36(14.3)$ & $31(17.5)$ \\
\hline Unemployed & $84(7.7)$ & $67(10.1)$ & $58(12.7)$ & $9(4.3)$ & $17(3.9)$ & $11(4.4)$ & $6(3.4)$ \\
\hline \multicolumn{8}{|l|}{ SES score tertile ${ }^{b}$} \\
\hline Low & $458(42.0)$ & $277(41.9)$ & $222(48.9)$ & 55 (26.6) & $181(42.2)$ & $111(44.0)$ & $70(39.5)$ \\
\hline Middle & $413(37.9)$ & $245(37.1)$ & $159(35.0)$ & $86(41.5)$ & $168(39.2)$ & $104(41.3)$ & $64(36.2)$ \\
\hline High & $219(20.1)$ & $139(21.0)$ & $73(16.1)$ & $66(31.9)$ & $80(18.6)$ & $37(14.7)$ & $43(24.3)$ \\
\hline \multicolumn{8}{|l|}{ Tobacco consumption $^{c}$} \\
\hline Never & $898(82.1)$ & $575(86.4)$ & $430(93.8)$ & $145(70.0)$ & $323(75.2)$ & $234(92.8)$ & $89(50.3)$ \\
\hline Ex-smoker & $105(9.6)$ & $61(9.2)$ & $14(3.1)$ & $47(22.7)$ & $44(10.3)$ & $4(1.6)$ & $40(22.6)$ \\
\hline Current & $91(8.3)$ & $29(4.4)$ & $14(3.1)$ & $15(7.2)$ & $62(14.5)$ & $14(5.6)$ & $48(27.1)$ \\
\hline \multicolumn{8}{|l|}{ Alcohol consumption $^{d}$} \\
\hline Never & $408(37.6)$ & $248(37.7)$ & $186(41.1)$ & $62(30.4)$ & $160(37.4)$ & $112(44.4)$ & $48(27.1)$ \\
\hline Ever $>1$ month & $383(35.3)$ & $255(38.9)$ & $183(40.4)$ & $72(35.3)$ & $128(29.7)$ & $80(31.7)$ & $48(27.1)$ \\
\hline Within $<1$ month & $295(27.1)$ & $154(23.4)$ & $84(18.5)$ & $70(34.3)$ & $141(32.9)$ & $60(23.9)$ & $81(45.8)$ \\
\hline \multicolumn{8}{|c|}{ Work involves moderate/vigorous activity ${ }^{\mathrm{e}}$} \\
\hline No & $494(45.2)$ & $433(65.1)$ & $333(72.7)$ & $100(48.3)$ & $61(14.3)$ & $48(19.0)$ & $13(7.4)$ \\
\hline Yes & $599(54.8)$ & $232(34.9)$ & $125(27.3)$ & $107(51.7)$ & $367(85.7)$ & $204(81.0)$ & $163(92.6)$ \\
\hline \multicolumn{8}{|l|}{ Days/week-animal proteins ${ }^{f}$} \\
\hline 0 & $300(27.6)$ & $127(19.3)$ & $98(21.6)$ & $29(14.1)$ & $173(40.3)$ & $123(48.8)$ & $50(28.2)$ \\
\hline 1 or 2 & $487(44.8)$ & $298(45.3)$ & $210(46.4)$ & $88(42.9)$ & $189(44.1)$ & $98(38.9)$ & $91(51.4)$ \\
\hline $3+$ & $300(27.6)$ & $233(35.4)$ & $145(32.0)$ & $88(42.9)$ & $67(15.6)$ & $31(12.3)$ & $36(20.4)$ \\
\hline \multicolumn{8}{|l|}{ Adds salt to food ${ }^{9}$} \\
\hline No & $625(57.8)$ & $399(61.0)$ & $283(63.0)$ & $116(56.6)$ & $226(52.8)$ & $148(58.7)$ & $78(44.3)$ \\
\hline Yes & $457(42.2)$ & $255(39.0)$ & $166(37.0)$ & $89(43.4)$ & $202(47.2)$ & $104(41.3)$ & $98(55.7)$ \\
\hline \multicolumn{8}{|c|}{ Type of oil/fat used in cooking ${ }^{h}$} \\
\hline None & $146(13.6)$ & $68(10.5)$ & $43(9.6)$ & $25(12.3)$ & $78(18.3)$ & $54(21.4)$ & $24(13.7)$ \\
\hline Vegetable oil & $793(73.6)$ & $488(75.1)$ & $334(74.9)$ & $154(75.5)$ & $305(71.4)$ & $183(72.6)$ & $122(69.7)$ \\
\hline Animal fat & $111(10.3)$ & $73(11.2)$ & $53(11.9)$ & $20(9.8)$ & $38(8.9)$ & $13(5.2)$ & $25(14.3)$ \\
\hline Others/none in particular & $27(2.5)$ & $21(3.2)$ & $16(3.6)$ & $5(2.5)$ & $6(1.4)$ & $2(0.8)$ & $4(2.3)$ \\
\hline
\end{tabular}


Table 2 continued

\begin{tabular}{|c|c|c|c|c|c|c|c|}
\hline \multirow[t]{3}{*}{ Characteristic } & \multirow{3}{*}{$\begin{array}{l}\text { All combined } \\
\text { n (\%) }\end{array}$} & \multicolumn{3}{|c|}{ Entebbe site } & \multicolumn{3}{|c|}{ Kyamulibwa site } \\
\hline & & \multirow[t]{2}{*}{ All, $n$ (\%) } & \multicolumn{2}{|l|}{ Sex } & \multirow[t]{2}{*}{ All, $n(\%)$} & \multicolumn{2}{|l|}{ Sex } \\
\hline & & & Females, n (\%) & Males, $\mathrm{n}(\%)$ & & Females, n (\%) & Males, n (\%) \\
\hline \multicolumn{8}{|c|}{ Total teaspoons of sugar added to drink/day } \\
\hline$<3$ & $337(31.5)$ & $247(38.4)$ & $149(33.7)$ & $98(48.8)$ & $90(21.0)$ & $46(18.3)$ & $44(25.0)$ \\
\hline $4 / 7$ & $428(39.9)$ & $279(43.4)$ & $202(45.7)$ & $77(38.3)$ & $149(34.8)$ & $84(33.3)$ & $65(36.9)$ \\
\hline $8+$ & $306(28.6)$ & $117(18.2)$ & $91(20.6)$ & $26(12.9)$ & $189(44.2)$ & $122(48.4)$ & $67(38.1)$ \\
\hline
\end{tabular}

All combined combines both Entebbe and Kyamulibwa sites. SES score tertile-Social Economic Status score computed from asset index based on household ownership of items

Number of participants with missing data: ${ }^{\mathrm{a} E m p l o y m e n t}-1,{ }^{\mathrm{b}} \mathrm{SES}$ score tertile- 5 , ${ }^{\mathrm{C}}$ Tobacco consumption -1 , ${ }^{\mathrm{d}}$ Alcohol consumption-9, ${ }^{\mathrm{e}}$ Work involves moderate/ vigorous activity $-2,{ }^{\mathrm{f}}$ Days/week-animal proteins $-8,{ }^{\mathrm{g}} \mathrm{Adds}$ salt to food- 13 , ${ }^{\mathrm{h}}$ Type of oil/fat used in cooking -18 , 'Total teaspoons of sugar added to drink/day- 24

Patients on non-PI containing ART regimen had higher diastolic hypertension than patients on PI containing ART regimen, $\mathrm{p}<0.001$ (Table 5).

\section{Discussion}

In sub Saharan Africa, there is paucity of data on the complications of long-term ART use generated from the region. The CoLTART cohort therefore provides a good platform to investigate the complications of long-term ART in a Ugandan population. In this cross-sectional analysis of data collected at enrolment of patients who had been on ART for a median of 9.4 years, we found no differences in renal function (eGFR and fractional tubular phosphate reabsorption) between patients on Tenofovir and Non-Tenofovir containing ART regimens. However, we found that patients on PI containing ART regimens had higher cardiometabolic risk factors including higher total cholesterol, lower high density lipoprotein, higher low density lipoprotein, higher triglycerides, and a high atherogenic index for plasma compared to the non-PI regimen.

These findings are reassuring against concerns about Tenofovir induced renal toxicity, especially as it is now recommended by WHO for initiating ART, and has been widely adopted by ART programmes in many resource limited countries including Uganda [12-15]. Short to medium follow up studies have reported an association between Tenofovir and renal dysfunction, leading to glomerular and proximal renal tubular damage and acute renal failure [17-20]. Our failure to find differences in renal dysfunction by Tenofovir use might be due to the fact that most of our patients had been on ART for more than 9 years. Similarly, other previous studies have reported that the loss in eGFR attributable to Tenofovir seemed to occur during the early years of exposure between 0.5 and 31.2 months and stabilized after that [38-41].

As HIV infected individuals live longer due to improved survival on ART, cardiometabolic co-morbidity will manifest, and the association of HIV infection and cardiovascular disease will be compounded by ART use. The association of PI containing ART regimen and cardiometabolic risk is important since PIs are the backbone of second line ART regimens in resource limited settings. With the advocacy and availability of virological monitoring of patients on ART, more patients with virological failure will be identified and switched to PI containing second line ART regimens. HIV care programmes in resource limited settings therefore need to integrate CVD risk assessment and preventive measures, including routine biochemical and biophysical monitoring as well as stocking of lipid lowering drugs, increasing physical exercises, dietary adjustments.

\section{Study strengths}

The CoLTART cohort study participants have been on ART for close to a decade and thus enables assessment of the temporal relationship between ART and ART complications. The DART and RCC cohorts have systematically collected data on clinical, immunological and virological treatment outcomes, ARV toxicities, with regular haematology, liver and kidney function biochemical test results that can be used retrospectively. Stored serum and plasma samples that can be used for various analyses for the status during the early ART period (DART) and during the Pre-ART and early ART periods (RCC) are also available. The MRC/UVRI Uganda Unit's CDLS has the capacity for analysing and storing research samples.

\section{Study weakness}

Study participants of the former cohorts may not be representative of the general HIV-positive population, and those who were available for enrolment may be a biased sample due to their longer survival. The study included limited outcomes, other long-term ART complications, such as reduced bone mineral density and osteoporosis were not studied due to the costs of the non-invasive DXA (DECK-sa) scan, a procedure used to measure bone 
Table 3 Medical history of participants at enrolment into the CoLTART study by sex and site

\begin{tabular}{|c|c|c|c|c|c|c|c|}
\hline \multirow[t]{3}{*}{ Medical condition } & \multirow{3}{*}{$\begin{array}{l}\text { All combined } \\
\text { n (\%) }\end{array}$} & \multicolumn{3}{|c|}{ Entebbe site } & \multicolumn{3}{|c|}{ Kyamulibwa site } \\
\hline & & \multirow[t]{2}{*}{ All, n (\%) } & \multicolumn{2}{|l|}{ Sex } & \multirow[t]{2}{*}{ All, n (\%) } & \multicolumn{2}{|l|}{ Sex } \\
\hline & & & Females, n (\%) & Males, n (\%) & & Females, n (\%) & Males, n (\%) \\
\hline All & 1095 & 666 & $459(68.9)$ & $207(31.1)$ & 429 & $252(58.7)$ & $177(41.3)$ \\
\hline \multicolumn{8}{|l|}{ Hypertension history } \\
\hline Never had hypertension & $936(85.5)$ & $556(83.5)$ & $378(82.4)$ & $178(86.0)$ & $380(88.6)$ & $222(88.1)$ & $158(89.3)$ \\
\hline Ever had hypertension & $159(14.5)$ & $110(16.5)$ & $81(17.6)$ & $29(14.0)$ & $49(11.4)$ & $30(11.9)$ & $19(10.7)$ \\
\hline \multicolumn{8}{|l|}{ Diabetes mellitus history ${ }^{a}$} \\
\hline No known diabetes mellitus & 1067 (97.9) & $645(97.3)$ & $445(97.4)$ & $200(97.1)$ & $422(98.8)$ & $248(98.8)$ & $174(98.9)$ \\
\hline Known diabetes mellitus & $23(2.1)$ & $18(2.7)$ & $12(2.6)$ & $6(2.9)$ & $5(1.2)$ & $3(1.2)$ & $2(1.1)$ \\
\hline \multicolumn{8}{|l|}{ Renal disease history ${ }^{\mathrm{b}}$} \\
\hline No renal disease & $1087(99.4)$ & $659(99.1)$ & $456(99.3)$ & $203(98.5)$ & $428(99.8)$ & $252(100.0)$ & $176(99.4)$ \\
\hline Known renal disease & $7(0.6)$ & $6(0.9)$ & $3(0.7)$ & $3(1.5)$ & $1(0.2)$ & $0(0.0)$ & $1(0.6)$ \\
\hline \multicolumn{8}{|l|}{ ART exposure, years } \\
\hline ART naïve & $74(6.8)$ & $27(4.1)$ & $21(4.6)$ & $6(2.9)$ & $47(11.0)$ & $22(8.7)$ & $25(14.1)$ \\
\hline$<1$ years & $79(7.2)$ & $13(2.0)$ & $11(2.4)$ & $2(1.0)$ & $66(15.4)$ & 35 (13.9) & $31(17.5)$ \\
\hline 1 to $<5$ years & $164(15.0)$ & $7(1.1)$ & $6(1.3)$ & $1(0.5)$ & $157(36.6)$ & $98(38.9)$ & $59(33.3)$ \\
\hline 5 to $<9$ years & $124(11.3)$ & $15(2.3)$ & $9(2.0)$ & $6(2.9)$ & $109(25.4)$ & $65(25.8)$ & $44(24.9)$ \\
\hline $9+$ years & $654(59.7)$ & $604(90.7)$ & $412(89.8)$ & $192(92.8)$ & $50(11.7)$ & $32(12.7)$ & $18(10.2)$ \\
\hline \multicolumn{8}{|c|}{ Metabolic abnormalities study groups ${ }^{c}$} \\
\hline Non-protease Inhibitor based ART & $785(76.9)$ & $432(67.6)$ & $306(69.9)$ & $126(62.7)$ & $353(92.4)$ & $212(92.2)$ & $141(92.8)$ \\
\hline Protease Inhibitor based ART & $236(23.1)$ & $207(32.4)$ & $132(30.1)$ & $75(37.3)$ & $29(7.6)$ & $18(7.8)$ & $11(7.2)$ \\
\hline \multicolumn{8}{|l|}{ Renal dysfunction study groups ${ }^{d}$} \\
\hline Tenofovir containing ART & 608 (59.6) & $500(78.3)$ & $337(76.9)$ & $163(81.1)$ & $108(28.3)$ & $64(27.8)$ & $44(29.0)$ \\
\hline Non-Tenofovir containing ART & $413(40.5)$ & $139(21.8)$ & $101(23.1)$ & $38(18.9)$ & $274(71.7)$ & $166(72.2)$ & $108(71.1)$ \\
\hline \multicolumn{8}{|l|}{ Body mass index $\left(\mathrm{kg} / \mathrm{m}^{2}\right)^{\mathrm{e}}$} \\
\hline$<18.5$ & $114(10.6)$ & $48(7.4)$ & $29(6.5)$ & $19(9.4)$ & $66(15.4)$ & $29(11.5)$ & $37(21.0)$ \\
\hline $18.5-24.9$ & $674(62.8)$ & $365(56.6)$ & $217(49.0)$ & $148(73.3)$ & $309(72.2)$ & $175(69.4)$ & $134(76.1)$ \\
\hline $25.0-29.9$ & $218(20.3)$ & $172(26.7)$ & $140(31.6)$ & $32(15.8)$ & $46(10.8)$ & $41(16.3)$ & $5(2.8)$ \\
\hline$\geq 30$ & $67(6.3)$ & $60(9.3)$ & $57(12.9)$ & $3(1.5)$ & $7(1.6)$ & $7(2.8)$ & $0(0.0)$ \\
\hline \multicolumn{8}{|l|}{ Haemoglobin $(\mathrm{g} / \mathrm{dl})^{\mathrm{f}}$} \\
\hline Normal & $908(83.3)$ & $570(86.2)$ & $387(85.1)$ & $183(88.8)$ & $338(78.8)$ & $199(79.0)$ & $139(78.5)$ \\
\hline Abnormal & $182(16.7)$ & $91(13.8)$ & $68(14.9)$ & $23(11.2)$ & $91(21.2)$ & $53(21.0)$ & $38(21.5)$ \\
\hline \multicolumn{8}{|c|}{ CD4 cell counts at enrolment $(\text { cells } / \mu)^{9}$} \\
\hline$\leq 350$ & $307(30.1)$ & $182(30.6)$ & $102(25.2)$ & $80(42.3)$ & $125(29.3)$ & $65(26.1)$ & $60(33.9)$ \\
\hline $351-500$ & $327(32.1)$ & $171(28.8)$ & $118(29.1)$ & $53(28.0)$ & $156(36.6)$ & $89(35.7)$ & $67(37.9)$ \\
\hline $501+$ & $386(37.8)$ & $241(40.6)$ & $185(45.7)$ & $56(29.6)$ & $145(34.0)$ & $95(38.2)$ & $50(28.2)$ \\
\hline \multicolumn{8}{|l|}{ Viral loads at enrolment $(\text { cells } / \mathrm{ml})^{\mathrm{h}}$} \\
\hline$\leq 1000$ copies $/ \mathrm{ml}$ & $823(77.7)$ & $528(81.6)$ & $363(81.2)$ & $165(82.5)$ & 295 (71.6) & $180(75.3)$ & $115(66.5)$ \\
\hline$>1000$ copies/ml & $236(22.3)$ & $119(18.4)$ & 84 (18.8) & 35 (17.5) & $117(28.4)$ & $59(24.7)$ & $58(33.5)$ \\
\hline
\end{tabular}

Number of participants with missing data: ${ }^{\mathrm{a} D i a b e t e s}$ mellitus history $-5,{ }^{\mathrm{b}}$ Renal disease history $-1,{ }^{\mathrm{c}}$ Metabolic abnormalities study groups -74 patients who were ART naïve at enrolment, ${ }^{d}$ Renal dysfunction study groups-74 patients who were ART naïve at enrolment, ${ }^{\mathrm{e} B o d y}$ Mass Index-22, ${ }^{\mathrm{f}} \mathrm{Haemog}$ lobin- 5 , ${ }^{9} \mathrm{CD} 4$ cell counts at enrolment -75 , hViral loads at enrolment-36; the 1059 included the 74 ART naïve individuals pending ART initiation

NNRTI nucleoside reverse transcriptase inhibitor, NNRTI non-nucleoside reverse transcriptase inhibitor

density, as well as mineral content in the body. In our study, a small number of patients; 50 (8.9\%) had discontinued Tenofovir but we did not consider the period since Tenofovir was discontinued and the reasons why it was discontinued. If Tenofovir was stopped due to Tenofovir induced renal dysfunction, this might have biased our results. Due to the low prevalence of antibody seropositivity and confirmed Hepatitis C virus (HCV) RNA infection in Uganda [42, 43], we did not screen for HCV in this study. Other potential sources of bias included the 
Table 4 Proportion of renal dysfunction/failure, and adjusted mean differences in renal function measures by TDF exposure among 964 adults on ART for more than 6 months

\begin{tabular}{|c|c|c|c|}
\hline Renal function assessment parameter & Renal dysfunction/failure, $\mathrm{n}(\%)$ & $\begin{array}{l}\text { Adjusted mean differences } \\
(95 \% \mathrm{Cl}) \text {, non-TDF as reference }\end{array}$ & $p$ value \\
\hline \multicolumn{4}{|l|}{ eGFR (Cockcroft-Gault, adj for BSA) } \\
\hline Non-TDF & $99 / 378(26.2 \%)$ & Ref & \multirow[t]{3}{*}{0.797} \\
\hline TDF & $142 / 501(28.3 \%)$ & $-2.15(-8.53$ to 4.22$)$ & \\
\hline TDF-stopped & $14 / 50(28.0 \%)$ & $-0.62(-12.74$ to 11.50$)$ & \\
\hline \multicolumn{4}{|l|}{ eGFR (Cockcroft-Gault, without BSA adj) } \\
\hline Non-TDF & $141 / 379(37.2 \%)$ & Ref & \multirow[t]{3}{*}{0.914} \\
\hline TDF & 196/502 (39.0\%) & $-2.42(-14.45$ to 9.62$)$ & \\
\hline TDF-stopped & 19/50 (38.0\%) & $-3.01(-25.90$ to 19.89$)$ & \\
\hline \multicolumn{4}{|l|}{ eGFR (CKD-Epi) } \\
\hline Non-TDF & $60 / 383(15.7 \%)$ & Ref & \multirow[t]{3}{*}{0.837} \\
\hline TDF & $109 / 514(21.2 \%)$ & $-0.88(-3.84$ to 2.08$)$ & \\
\hline TDF-stopped & $9 / 50(18.0 \%)$ & $-0.78(-6.42$ to 4.87$)$ & \\
\hline \multicolumn{4}{|l|}{ eGFR (MDRD with race) } \\
\hline Non-TDF & $28 / 383(7.3 \%)$ & Ref & \multirow[t]{3}{*}{0.872} \\
\hline TDF & $57 / 514(11.1 \%)$ & $-0.61(-8.09$ to 6.87$)$ & \\
\hline TDF-stopped & $4 / 50(8.0 \%)$ & $3.11(-11.14$ to 17.36$)$ & \\
\hline \multicolumn{4}{|l|}{ Fractional tubular $\mathrm{PO} 4$ reabsorption } \\
\hline Non-TDF & $16 / 339(4.7 \%)$ & Ref & \multirow[t]{3}{*}{0.131} \\
\hline TDF & $16 / 386(4.1 \%)$ & $-0.74(-1.84$ to 0.36$)$ & \\
\hline TDF-stopped & $1 / 42(2.4 \%)$ & $1.12(-0.92$ to 3.15$)$ & \\
\hline \multicolumn{4}{|l|}{ Serum urea } \\
\hline Non-TDF & 0/382 (0.0\%) & Ref & \multirow[t]{3}{*}{0.252} \\
\hline TDF & $2 / 514(0.4 \%)$ & $0.03(-0.19$ to 0.25$)$ & \\
\hline TDF-stopped & 0/50 (0.0\%) & $0.35(-0.07$ to 0.77$)$ & \\
\hline \multicolumn{4}{|l|}{ Serum creatinine $(\mu \mathrm{mol} / \mathrm{l})$} \\
\hline Non-TDF & 4/383 (1.0\%) & Ref & \multirow[t]{3}{*}{0.336} \\
\hline TDF & 10/514 (1.9\%) & $2.03(-1.40$ to 5.46$)$ & \\
\hline TDF-stopped & $3 / 50(6.0 \%)$ & $3.98(-2.55$ to 10.51$)$ & \\
\hline \multicolumn{4}{|l|}{ Serum phosphates $(\mathrm{mmol} / \mathrm{l})$} \\
\hline Non-TDF & $64 / 383(16.7 \%)$ & Ref & \multirow[t]{3}{*}{0.575} \\
\hline TDF & $50 / 503(9.9 \%)$ & $0.01(-0.04$ to 0.06$)$ & \\
\hline TDF-stopped & 8/48 (16.7\%) & $-0.04(-0.13$ to 0.05$)$ & \\
\hline
\end{tabular}

Mean difference adjusted for site, duration on ART, smoking status, social-economic status, log viral load, CD4 cell count, hypertension and Glucose; Renal dysfunction/failure defined as $<90$ for estimated Glomerular Filtration Rates, $>11.9 \mathrm{mmol} / \mathrm{l}$ for serum Urea, $>109 \mu \mathrm{mol} / \mathrm{l}$ for serum creatinine and $<0.81 \mathrm{mmol} / \mathrm{l}$ for serum phosphates (Hypophosphataemia)

eGFR estimated glomerular filtration rate, BSA body surface area adjustment, CKD-Epi Chronic Kidney Disease Epidemiology formula, MDRD Modified Diet in Renal Disease formulae with race adjustment

self-reported thus subjectively measured individual level exposures especially dietary, socio-economic and behavioural factors. There might have been some inaccuracies in tracking time on particular regimens of ART e.g. the exact dates of ART switches or substitutions.

\section{Conclusions}

Our findings allay fears of Tenofovir renal toxicity and the WHO recommendation to use Tenofovir in first line ART can safely be implemented even in resource limited settings with limited renal function monitoring. However, further evaluation of renal function among patients on Tenofovir beyond 10 years is advised. Integration of cardiovascular risk assessment, institution of preventive and curative or control remedies against cardiovascular disease are recommended.

\section{Data available}

Data available includes demographic, social economic status, medical, dietary and lifestyle risk factors. Biophysical measurements data available includes weight, height, blood pressure and pulse rate; waist, hip and mid-upper 
Table 5 Proportion of abnormal values for CVD risk factors and differences in mean values of CVD risk measures by PI exposure among the 964 adults on ART for more than 6 months

\begin{tabular}{|c|c|c|c|}
\hline CVD risk measure & $\begin{array}{l}\text { Abnormal values } \\
\text { for CVD risk, } n(\%)\end{array}$ & $\begin{array}{l}\text { ADJUSTED mean differences } \\
(95 \% \mathrm{Cl}) \text {, non- } \mathrm{PI} \text { as reference }\end{array}$ & p value \\
\hline \multicolumn{4}{|c|}{ Total cholesterol $\geq 5.2 \mu \mathrm{mol} / \mathrm{l}$} \\
\hline Non-PI regimen & $176 / 714(24.6 \%)$ & Ref & \multirow[t]{2}{*}{$<0.001$} \\
\hline PI regimen & $121 / 230(52.6 \%)$ & 0.78 (0.57 to 0.98$)$ & \\
\hline \multicolumn{4}{|c|}{$\mathrm{HDL}<1 \mathrm{mmol} / \mathrm{l}$ (males), $<1.3 \mathrm{mmol} / \mathrm{l}$ (females) } \\
\hline Non-PI regimen & 265/714 (37.1\%) & Ref & \multirow[t]{2}{*}{0.001} \\
\hline PI regimen & $67 / 230(29.1 \%)$ & $0.12(0.05$ to 0.20$)$ & \\
\hline \multicolumn{4}{|l|}{$\mathrm{LDL} \geq 3.4 \mathrm{mmol} / \mathrm{l}$} \\
\hline Non-PI regimen & $144 / 714(18.6 \%)$ & Ref & \multirow[t]{2}{*}{$<0.001$} \\
\hline PI regimen & $93 / 230(40.3 \%)$ & 0.45 (0.29 to 0.62$)$ & \\
\hline \multicolumn{4}{|c|}{ Total cholesterol/HDL ratio (>5.1) } \\
\hline Non-PI regimen & $90 / 714(12.6 \%)$ & Ref & \multirow[t]{2}{*}{0.420} \\
\hline PI regimen & $42 / 230(18.3 \%)$ & $0.10(-0.15$ to 0.35$)$ & \\
\hline \multicolumn{4}{|c|}{ Triglycerides $\geq 1.69 \mathrm{mmol} / \mathrm{l}$} \\
\hline Non-PI regimen & 109/713 (15.3\%) & Ref & \multirow[t]{2}{*}{$<0.001$} \\
\hline PI regimen & $99 / 230(43.0 \%)$ & 0.52 (0.24 to 0.80$)$ & \\
\hline \multicolumn{4}{|c|}{ Glucose (>6.4 mmol/l) } \\
\hline Non-PI regimen & $26 / 714(3.6 \%)$ & Ref & \multirow[t]{2}{*}{0.814} \\
\hline PI regimen & 7/231 (3.0\%) & $0.00(-0.03$ to 0.04$)$ & \\
\hline \multicolumn{4}{|c|}{ Systolic blood pressure ( $\geq 140 \mathrm{mmHg}$ ) } \\
\hline Non-PI regimen & 110/707 (15.6\%) & Ref & \multirow[t]{2}{*}{0.060} \\
\hline PI regimen & 19/234 (8.1\%) & $-3.120(-6.413$ to 0.174$)$ & \\
\hline \multicolumn{4}{|c|}{ Diastolic blood pressure ( $\geq 90 \mathrm{mmHg}$ ) } \\
\hline Non-PI regimen & $112 / 707(15.8 \%)$ & Ref & \multirow[t]{2}{*}{$<0.001$} \\
\hline PI regimen & 13/234 (5.6\%) & $-3.931(-5.967$ to 1.895$)$ & \\
\hline \multicolumn{4}{|c|}{ AIP $\log _{10}$ (Triglycerides/HDL) $\geq 0.1$} \\
\hline Non-PI regimen & $183 / 713(25.7 \%)$ & Ref & \multirow[t]{2}{*}{$<0.001$} \\
\hline PI regimen & $102 / 230(44.3 \%)$ & 0.12 (0.07 to 0.17$)$ & \\
\hline \multicolumn{4}{|c|}{ Abnormal BMI ( $\left.\geq 30 \mathrm{~kg} / \mathrm{m}^{2}\right)$} \\
\hline Non-PI regimen & 44/703 (6.3\%) & Ref & \multirow[t]{2}{*}{0.074} \\
\hline PI regimen & 17/231 (7.3\%) & $-2.370(-5.005$ to 0.264$)$ & \\
\hline \multicolumn{4}{|c|}{ Abnormal waist circumference $[\geq 94 \mathrm{~cm}$ (men)/ $\geq 80$ (women)] } \\
\hline Non-PI regimen & $287 / 706(40.6 \%)$ & Ref & \multirow[t]{2}{*}{0.805} \\
\hline PI regimen & $94 / 234(40.2 \%)$ & $-0.202(-1.829$ to 1.425$)$ & \\
\hline \multicolumn{4}{|c|}{ Abnormal waist/hips ratio [>0.95 (men)/>85 (women)] } \\
\hline Non-PI regimen & $369 / 706(52.3 \%)$ & Ref & \multirow[t]{2}{*}{0.118} \\
\hline Pl regimen & $133 / 234(56.8 \%)$ & $0.008(-0.002$ to 0.019$)$ & \\
\hline \multicolumn{4}{|c|}{ Abnormal Framingham score (>10\%) } \\
\hline Non-PI regimen & 130/703 (18.5\%) & Ref & \multirow[t]{2}{*}{0.434} \\
\hline PI regimen & $28 / 229(12.2 \%)$ & $-0.344(-1.218$ to 0.530$)$ & \\
\hline
\end{tabular}

Mean differences adjusted for site, duration on ART, sex, age-groups, smoking status, alcohol consumption, days/week-animal proteins, salt and sugar intake, physical activity, social-economic status, log viral load, CD4 cell count

$H D L$ high density lipoprotein, LDL Low Density Lipoprotein, AIP atherogenic index for plasma, BMI body mass index

arm circumferences. Clinical examination and ART and cotrimoxazole/dapsone adherence data is also available. Available laboratory data includes: fasting blood glucose and lipid profiles (total cholesterol, triglycerides, low density lipoproteins, high density lipoproteins); renal function tests (Urine strip test, phosphates and creatinine and serum phosphates, creatinine and urea). Full blood counts, immunology (CD3, CD4 and CD8), viral loads and HIV drug resistance test results for blood samples with viral loads $\geq 1000$ copies/ml. Liver function tests (alanine 
transaminase, aspartate transaminase, alkaline phosphatase and bilirubin). Stored samples are also available for Hepatitis B virus serology, genomic studies and other studies.

\section{Data resource access}

The CoLTART database has data on the participants biophysical measurements, clinical examination findings and laboratory measurements. All data from the cohort are managed by the Statistics Section of the MRC/UVRI Uganda Research Unit on AIDS. Data access inquiries can be made to the Director, MRC/UVRI, Uganda Research Unit on AIDS by email to: mrc@mrcuganda.org or the corresponding author.

\begin{abstract}
Abbreviations
AIDS: Acquired Immune Deficiency Syndrome; ART: antiretroviral therapy; ARVs: antiretroviral drugs; CAP: College of American Pathologists; CDLS: Clinical Diagnostics Laboratory Services; CRFs: case report forms; CoLTART: Complications of Long-Term Antiretroviral Therapy; CPR: calibrated population resistance tool; CVD: cardiovascular disease; DART: Development of Antiretroviral therapy in Africa; DXA: dual-energy X-ray absorptiometry; EDTA: ethylenediaminetetraacetic acid; eGFR: estimated glomerular filtration rate; GCP: Good Clinical Practice; HIV: human immunodeficiency virus; ICH: International Council for Harmonisation; MRC: Medical Research Council; NRTI: Nucleoside Reverse Transcriptase Inhibitors; NNRTI: Non Nucleoside Reverse Transcriptase Inhibitors; PCR: Polymerase Chain Reaction; PI: protease inhibitor; RCC: Rural Clinical Cohort; RCPA: Royal College of Pathologists of Australasia; RMD: Roche Molecular Diagnostics; RNA: ribonucleic acid; SDRMs: surveillance drug resistance mutations; STEPS: STEPwise approach to surveillance; TDF: Tenofovir Disoproxil Fumarate; TDR: transmitted drug resistance; UKNEQAS: United Kingdom National External Quality Assurance Service; UVRI: Uganda Virus Research Institute; WHO: World Health Organisation.
\end{abstract}

\section{Authors' contributions}

BNM, JL, PM, PK conceived and designed the study; BNM, IN, PK, JW participated in data collection; JW participated in the laboratory analyses; IK, JL compiled and analysed data; BNM, IK, drafted the initial manuscript; BNM, IK, PM, PK interpreted the analysis; all authors contributed to manuscript revising. All authors read and approved the final manuscript.

\section{Author details}

1 MRC/UVRI Uganda Research Unit on AIDS, P.O. Box 49, Entebbe, Uganda. ${ }^{2}$ MRC Tropical Epidemiology Group, London School of Hygiene and Tropical Medicine, Keppel Street, London WC1E 7HT, United Kingdom. ${ }^{3}$ Department of Clinical Research, London School of Hygiene and Tropical Medicine, Keppel Street, London WC1E 7HT, United Kingdom.

\section{Acknowledgements}

We acknowledge the contribution of CoLTART study participants, the CoLTART study team, and staff of the Clinical Diagnostic Laboratory Services, Basic Science and Statistics section. We also acknowledge the contribution of the MRC/UVRI Uganda Unit's Scientific Advisory Committee.

\section{The CoLTART study team}

Kyamulibwa study site: Billy N. Mayanja, Judith Nalwadda, Gladys Nakibuuka, Harriet Namugenyi, Patrick Kazooba, Rosemary Lubega. Entebbe study site: Annet Mugisha, Apophia Tereka, Apuuli Kalyebara, Arthur Namara, Diana Nakitto, Deus Wangi, Fred Nume, George Ssemwanga, Gertrude Nabulime, Gladys Nassuna, Gloria Lubega, Ivan Namakoola, Joseph Lutaakome, Lillian Generous, Lydia Matama, Rosemary Massa, Salome Tino, William Nakahima. Basic Science Virology: Anne A. Kapaata, Brian Magambo, Chris Parry, Frederick Lyagoba, Jamirah Nazziwa, Maria Nannyonjo. Clinical Diagnostic Laboratory Services: Edward Muhigirwa, Faith Wamalugu, Florence Kabajuma, Hope Grania Nakazibwe, Jackson Were, Joan Bwandinga, Juliet Bukenya, Member Zephyrian Kamushaaga, Peter Hughes, Peter Nkurunziza, Priscilla Agatha Balungi,
Simon Mukasa, Sureyah Nassimbwa, Tobias Vudriko, William Senyonga, WilIyfred Ochola. Statistics: Annet Nakimbugwe, Catherine Nampewo, Doreen Nambuba, Erima Naphtali, Grace Barigye, Irene Nakamanya, Ivan Kasamba, Jonathan Levin, Joseph Kahwa, Joy Namutebi Matovu, Lillian Namayirira, Ruth Namulindwa Lubega, Sandra Nabalayo, Solomon Kaddu. Principal Investigator: Paula Munderi.

\section{Competing interests}

The authors declare that they have no competing interests.

\section{Availability of data and materials}

Data will not be shared publicly due to the data sharing policy of the MRC/ UVRI Uganda Research Unit on AIDS, which requires a prior data sharing agreement. However, a full data set on the CoLTART study containing the data supporting the study findings in this report can be obtained from the Director, by email to: mrc@mrcuganda.org or the corresponding author.

\section{Ethics approval and consent to participate}

The CoLTART study was approved by the Uganda Virus Research Institute Research and Ethics Committee and the Uganda National Council for Science and Technology. Participants gave informed signed (or witnessed thumbprinted) written consent to participate in the study, which was conducted in compliance with the study protocol, ICH GCP and local regulatory requirements. Throughout the study, we ensured participants' privacy and confidentiality while use of unique identification and laboratory numbers ensured their anonymity. Refusal to participate did not affect one's normal medical and HIV care which was provided according to the National guidelines. Participants were reimbursed their transport costs.

\section{Funding}

This research was jointly funded by the UK Medical Research Council (MRC) and the UK Department for International Development (DFID) under the MRC/DFID Concordant agreement.

\section{Publisher's Note}

Springer Nature remains neutral with regard to jurisdictional claims in published maps and institutional affiliations.

Received: 7 December 2016 Accepted: 28 April 2017

Published online: 04 May 2017

\section{References}

1. UNAIDS. Fact sheet November 2016. http://www.unaids.org/en/ resources/fact-sheet. Accessed 3 Dec 2016.

2. UNAIDS. The HIV and AIDS Uganda Country Progress Report 2014. http:// www.unaids.org/sites/default/files/country/documents/UGA_narrative_report_2015.pdf. Accessed 6 Oct 2015.

3. Maher D, Waswa L, Baisley K, Karabarinde A, Unwin N. Epidemiology of hypertension in low-income countries: a cross-sectional populationbased survey in rural Uganda. J Hypertens. 2011;29:1061-8.

4. Bimenya G, Okot J, Nangosa H, Anguma S, Byarugaba W. Plasma cholesterol and related lipid levels of seemingly healthy public service employees in Kampala, Uganda. Afr Health Sci. 2006;6:139-44.

5. Haugaard SB. Toxic metabolic syndrome associated with HAART. Expert Opin Drug Metab Toxicol. 2006;2:429-45.

6. Hofman P, Nelson AM. The pathology induced by highly active antiretroviral therapy against human immunodeficiency virus: an update. Curr Med Chem. 2006;13:3121-32.

7. Bradbury RA, Samaras K. Antiretroviral therapy and the human immunodeficiency virus - improved survival but at what cost? Diabetes Obes Metab. 2008;10:441-50.

8. Montessori V, Press N, Harris M, Akagi L, Montaner JS. Adverse effects of antiretroviral therapy for HIV infection. CMAJ. 2004;170:229-38.

9. Herman JS, Easterbrook PJ. PJ E. The metabolic toxicities of antiretroviral therapy. Int J STD AIDS. 2001;12:555-62.

10. Post FA, Holt SG. SG H. Recent developments in HIV and the kidney. Curr Opin Infect Dis. 2009;22:43-8. 
11. Roling J, Schmid H, Fischereder M, Draenert R, Goebel FD. HIV-associated renal diseases and highly active antiretroviral therapy-induced nephropathy. Clin Infect Dis. 2006;42:1488-95.

12. WHO. Consolidated guidelines on the use of antiretroviral drugs for treating and preventing HIV infection. Geneva: World Health Organization; 2013. http://www.who.int/hiv/pub/guidelines/arv2013. Accessed 26 Jan 2016.

13. Ministry of Health U. Addendum to the National Antiretroviral Treatment Guidelines. 2013. http://preventcrypto.org/wp-content/ uploads/2012/07/Uganda-National-ART-Guidelines_2014.pdf. Accessed 15 Jan 2015.

14. Ministry of Health, Republic of Kenya, (NASCOP). NAaSCP: guidelines on use of antiretroviral drugs for treating and preventing HIV infection: a rapid advice. 2014. http://guidelines.health.go.ke:8000/media/Rapid_ Advice_Booklet_2014_July_V5.pdf. Accessed 17 Feb 2016.

15. Ministry of Health and Social Welfare, Tanzania TURo. NACProgramme: the United Republic of Tanzania. National Guidelines for the Management of HIV and AIDS. Fifth Edition-May, 2015. http://www.nacp.go.tz/site/publications/care-and-treatment/NationalGuidelineforManagementHIV.pdf. Accessed 15 Feb 2016.

16. Jülg BD, Bogner JR, Crispin A, Goebel FD. Progression of renal impairment under therapy with tenofovir. AIDS. 2005;19:1332-3.

17. Zimmermann AE, Pizzoferrato T, Bedford J, Morris A, Hoffman R, Braden G. Tenofovir-associated acute and chronic kidney disease: a case of multiple drug interactions. Clin Infect Dis. 2006;42:283-90.

18. Gallant JE, Winston JA, DeJesus E, Pozniak AL, Chen S-S, Cheng AK, et al. The 3-year renal safety of a tenofovir disoproxil fumarate vs. a thymidine analogue-containing regimen in antiretroviral-naive patients. AIDS. 2008;22:2155-63.

19. Ryom L, Mocroft A, Kirk O, Worm SW, Kamara DA, Reiss P, et al. Association between antiretroviral exposure and renal impairment among HIVpositive persons with normal baseline renal function: the D: A: D Study. J Infect Dis. 2013;207:1359-69.

20. Labarga P, Barreiro P, Martin-Carbonero L, Rodriguez-Novoa S, Solera C, Medrano J, et al. Kidney tubular abnormalities in the absence of impaired glomerular function in HIV patients treated with tenofovir. AIDS. 2009;23:689-96.

21. Laprise C, Baril J-G, Dufresne S, Trottier H. Association between tenofovir exposure and reduced kidney function in a cohort of HIVpositive patients: results from 10 years of follow-up. Clin Infect Dis. 2012;56:567-75.

22. Oboho I, Abraham A, Benning L, Anastos K, Sharma A, Young M, et al. Tenofovir use and urinary biomarkers among HIV-infected women in the Women's Interagency HIV Study (WIHS). J Acquir Immune Defic Syndr. 2013;62:388-95.

23. Gupta SK. Tenofovir-associated Fanconi syndrome: review of the FDA adverse event reporting system. AIDS Patient Care STDS. 2008;22:99-103.

24. Cm W. HIV and the kidney: a spotlight on racial disparities. J Infect Dis. 2008;197:1490-2

25. Mugyenyi P, Walker AS, Hakim J, Munderi P, Gibb DM, Kityo C, et al. Routine versus clinically driven laboratory monitoring of HIV antiretroviral therapy in Africa (DART): a randomised non-inferiority trial. Lancet. 2010;375:123-31.

26. Morgan D, Malamba SS, Maude GH, Okongo MJ, Wagner HU, Mulder DW, et al. An HIV-1 natural history cohort and survival times in rural Uganda. AIDS. 1997;11:633-40.

27. Shafer LA, Nsubuga RN, White R, Mayanja BN, Chapman R, O'Brien K, et al. Antiretroviral therapy and sexual behavior in Uganda: a cohort study. AIDS. 2011;25:671-8.
28. Mayanja BN, Todd J, Hughes P, Van der Paal L, Mugisha JO, Atuhumuza E, et al. Septicaemia in a population-based HIV clinical cohort in rural Uganda, 1996-2007: incidence, aetiology, antimicrobial drug resistance and impact of antiretroviral therapy. Trop Med Int Health Trop Med Int Health. 2010;15:697-705.

29. Iwuji CC, Mayanja BN, Weiss HA, Atuhumuza E, Hughes P, Maher D, et al. Morbidity in HIV-1-infected individuals before and after the introduction of antiretroviral therapy: a longitudinal study of a population-based cohort in Uganda. HIV Med. 2011;12:553-61.

30. Mayanja BN, Baisley K, Nalweyiso N, Kibengo FM, Mugisha JO, Van der Paal L, et al. Using verbal autopsy to assess the prevalence of HIV infection among deaths in the ART period in rural Uganda: a prospective cohort study, 2006-2008. Popul Health Metr. 2011;9:36.

31. Asiki G, Murphy G, Nakiyingi-Miiro J, Seeley J, Nsubuga RN, Karabarinde A, et al. The general population cohort in rural south-western Uganda: a platform for communicable and non-communicable disease studies. Int J Epidemiol. 2013;42:129-41.

32. French N, Nakiyingi J, Carpenter L, Lugada E, Watera C, Moi K, et al. 23valent pneumococcal polysaccharide vaccine in HIV-1-infected Ugandan adults: double-blind, randomised and placebo controlled trial. Lancet. 2000;355:2106-11.

33. Ministry of Health, Uganda. Integrated national guidelines on antiretroviral therapy, prevention of mother to child transmission of HIV and on infant \& young child feeding. First Edition, June 2011. http://www. emtct-iatt.org/wp-content/uploads/2014/05/GL_Integrated-NationalGuidelines-on-ART-PMTCT-and-IYCF-June-2011-MOH-Uganda_0.pdf. Accessed 27 Sept 2015.

34. Asiki G, Murphy GA, Baisley K, Nsubuga RN, Karabarinde A, Newton R, et al. Prevalence of dyslipidaemia and associated risk factors in a rural population in South-Western Uganda: a community based survey. PLoS ONE. 2015;10(5):e0126166.

35. WHO. Chronic diseases and health promotion, STEPwise approach to chronic disease risk factor surveillance. http://www.who.int/chp/steps/ nauru/en/. Accessed 23 Sept 2015.

36. Bennett DE, Camacho RJ, Otelea D, Kuritzkes DR, Fleury H, Kiuchi M, et al. Drug resistance mutations for surveillance of transmitted HIV-1 drugresistance: 2009 update. PLoS ONE. 2009;4:e4724.

37. Gifford RJ, Liu TF, Rhee SY, Kiuchi M, Hue S, Pillay D, et al. The calibrated population resistance tool: standardized genotypic estimation of transmitted HIV-1 drug resistance. Bioinformatics. 2009;25:1197-8.

38. Izzedine H, Isnard-Bagnis C, Hulot J-S, Vittecoq D, Cheng A, Jais CK, et al. Renal safety of tenofovir in HIV treatment-experienced patients. AIDS. 2004;18:1074-6.

39. Kyaw NTT, Harries AD, Chinnakali P, Antierens A, Soe KP, Woodman M, et al. Low incidence of renal dysfunction among HIV-infected patients on a Tenofovir-based first line antiretroviral treatment regimen in Myanmar. PLoS ONE. 2015;10:e0135188.

40. Nelson MR, Katlama C, Montaner JS, Cooper DA, Gazzard B, Clotet B, et al. The safety of tenofovir disoproxil fumarate for the treatment of HIV infection in adults: the first 4 years. AIDS. 2007;21:1273-81.

41. Madeddu G, Bonfanti P, Giuseppe V, Carradori S, Grosso C, Marconi P, et al. Tenofovir renal safety in HIV-infected patients: results from the SCOLTA project. Biomed Pharmacother. 2008;62:6-11.

42. O'Reilly Jl, Ocama P, Opio CK, Alfred A, Paintsil E, Seremba E, et al. Risk factors and seroprevalence of hepatitis $C$ among patients hospitalized at Mulago Hospital, Uganda. J Trop Med. 2011;2011:598341.

43. Walusansa V, Kagimu M. Screening for hepatitis $C$ among HIV positive patients at Mulago hospital in Uganda. Afr Health Sci. 2009;9:143-6. 